44 Guyo?, über die Bereitung des hydriodsauren Bleiiodiurs.

Ghennen, ob Sublimat mit Doppelt-Bromquecksiber gemischt sey. Dic zu diesem Zweck angestcllten Versuche zeigten mir, daft $1 / s$ und selbst $1 / 10$ dan Deppelt - Brompuechsiber zugesetzteł Subhinat entdecht werden kbnine durch die weifse Trü. bung und den teichten Niederschlag, welchen eine Eiweifsanflosang veranlalste in einer Aulkösung, in welcher sich beills Verbindangen im oben angegehenen Verhaitnisse befandon.

Fis geht aus diesen thatsachen hervor: a dals das Doppek-13romiquecksilber int Wasser weniger löslieh ist als Subti. mat; 2) dafs Wasser voth $+9^{3} 105 / 10$ hom oder nngelihr $1 / 1,0$ davon suffost; 7) dars das Eiweils thit Buppelt-Bromquecksilber eine Verbondung hildet, wekhe nofgelöst bleition hann, wenn die 1 dsung ntit dem 3ofachen Gewicht Whseer verdinnt ist; 4) dals bri dlesem Grade der Verdlinnung elne Sublimat. autlosung getritht und nucb oinlger Zeit präctpitirt wirt; 5) dafs die Nicht-Präcipitationn elner verdinnten Auflounng von Doppelt-Bromquectsilber durch Fiweifs nicht alleln zur Unterscheidung von einer Suhlimatloung dienen kann, sondern dafo auch möglich ist zu erkennen, ob das Boppel-Gromür mit Sublimat in oben angegubenen Verhältnissen gemischt ise (Journ. de Chimie med. Arril ı896. S. '77.)

\title{
Ueber die Bereitung des hydriodsauren Bleiiodürs ;
}

von Guyot, Apotheker in Paris.

Nach den zahtreichen Untersuchungen ron Hrn. Bouliay Bohn iber die Doppeliodüre, in seiner 1827 der Acall. des sciences vorgelesenen Abhandlung hleibt mir nichts ïber diese aus a binären Verbindungen gebildeten Körper zu erwähnen iibrig: es wurde dieser Gegensiand nach allen nur möglichen 
Guyor, über die Bereilung des hydriodsauren Bleüodiurs. $\$ 5$

nichtungen aligehandelt, und meine Absicht ist hier nur die Bereifung und die Eigenschaften des hydriodsauren Bleijodïrs anzuführen, welches in seinen Eigenschaften ron dem, von Boullay so gut beschriebenen, hydriodsauran Quecksilberiodür wenig abweicht.

Die Bereitung des hydriodsauren Bleiiodürs grĩndet sich nuf die Wirkung der llydriodsäure aut das metallische Blei, und fotglich auf das Bleiiodür.

Man erhält es, wenn man in cinem Porccllangefüfse gefeilles Blei mit einem Ueberschufs concentrirter Hydriodsäure zusaunrenbringt, und der Inft aussetzt.

Bei Einwirkung dar Luft an Hydriodsiture verliert diese eine gewisse Menge Iod, welche sich anf das Blei wirft und damit Fleiiodïr bildet, ein 'Theil daron geht zu gleicher Zeit In hydriodsaures Bleiiodür über. Während der ganzen Dauer Jer Operation findet dieselbe Reaction Statt. Bei Beendigung der Einwirlung, immer bei Luftzutritt und obne Wärme anzuwenden, erhält man am Boden des Gefälses weifse, seidenartige Krystalle. Bein Erhitzen bis zum Kochpantite in dè Mutterlaugc bilden sich beim Erkalten viel wenıger schone Krystalle.

lch exhielt gleichfalls hydriodsaures Bleiiodif, wenn ich Bleiiodïr in einem Ueberschufs cuncentrirter Hydriodsăure bei gelinder Wärme hehandelte.

Das hydriodsaure Bleiiodür scheint aus ennem Atom Btesiodür und zwei d lomen Hydriodsäure zusammengesetzt zu seyn.

Wie seloon oben angefiihrt, lizystallisirt das hydriodsause Bleiiodiir in weifsen, seidenartigen Nadeln; durch Wârme wird es in Bleiiodür und in Hydriodsäure zersetzt, welche

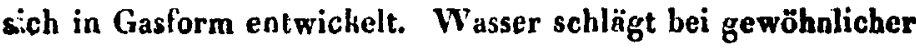
Temperatur eine beträchtliche Menge Bleiiodür nieder und es bleibt nur sehr wenig hydriodsaures Bleiiodür in Auflösung. 
Hochendes Wasser zersetzt es vollständig; es entweicht alle Hydriodsäure and beim Erhalten krystallisirt Bleiiodür heraus.

Trockene Luft bewirlit beunerbliche Veränderung, welche mit Folliger Zersetzung endigt.

Mehrere unter der Iuftpumpe angestellte Versuche zeigten mir, dafs die Hydriodsäure dadurch ron dem Bleiindür geschieden wird.

(Joura. de Climle nedic. Mai 1836. S. 247.)

\section{$\longrightarrow$ \\ Ueher das Glycerin; \\ von J. Pelouze. $\left.{ }^{*}\right)$}

Das Glycerin ist eine unhrystallisirbare Flüssigheit von sehr schwach gelblicher Farbe, ohno Geruch und von deutlich süfsem Geschnack; das spec. Gewicht ist bei $+15^{\circ}=$ 1,28 , es ist in jedem Verhäitnifs in Wasser und Alkohol lös. lich, unlöslich in Aether. Einer höheren l'emperatur ausgesetzt trennt es sich in a Theile, woron sich dex eine ohne Veränderung verflïchtigt und der andere sich in brenzliches $\mathrm{Ocl}$, Essigsüure, brenubares Gas und in einen liohligen Rückstand ecrsetzt. Das Clycer in löst, ohngeaehtet seiner beinahe festen Deschaffenheit, viele Körper auf, namentlich vegetabilische Süuren, alle zerlliefslichen Salze, viele andere, die es nicht sind, als schwefelsaures Kali, Natron, Kupferoxyd, salpetersaures Silberoxyd and Hali, die Cblorüre der Allalien, unter dea Basen das Kali und Natron in beträchtlicher Menge,

-) Wir haben schon Bd. XIX. S. zio. einen Auszug diescr Abhand. lung gegebeu, und es haun nun der Auszug dieser, uns rou Hru. Pelu u\%e mitgetheilten Notiz als der analytische Theil und als Vervollstäadigung àes fritheren Aussugs betraclitet werden.

D. $\mathbf{K}$. 